\title{
Color Assessment
}

National Cancer Institute

\section{Source}

National Cancer Institute. Color Assessment. NCI Thesaurus. Code C64546.

A qualitative assessment of the color of a biological specimen. 